\title{
Introduction to the life of Prof. Dr. Franz Oberwinkler (22 May 1939-15 March 2018)
}

\section{Takayuki Aoki ${ }^{1}$}

Published online: 31 July 2018

(c) School of Science 2018

It was for me an unexpected, unhappy announcement, concerning the severe disease that the late Dr. Franz Oberwinkler had been diagnosed, sent from one of his former students in early February 2018. He suffered from a brain tumor and passed away at home very suddenly, surrounded by his beloved family (Fig. 1).

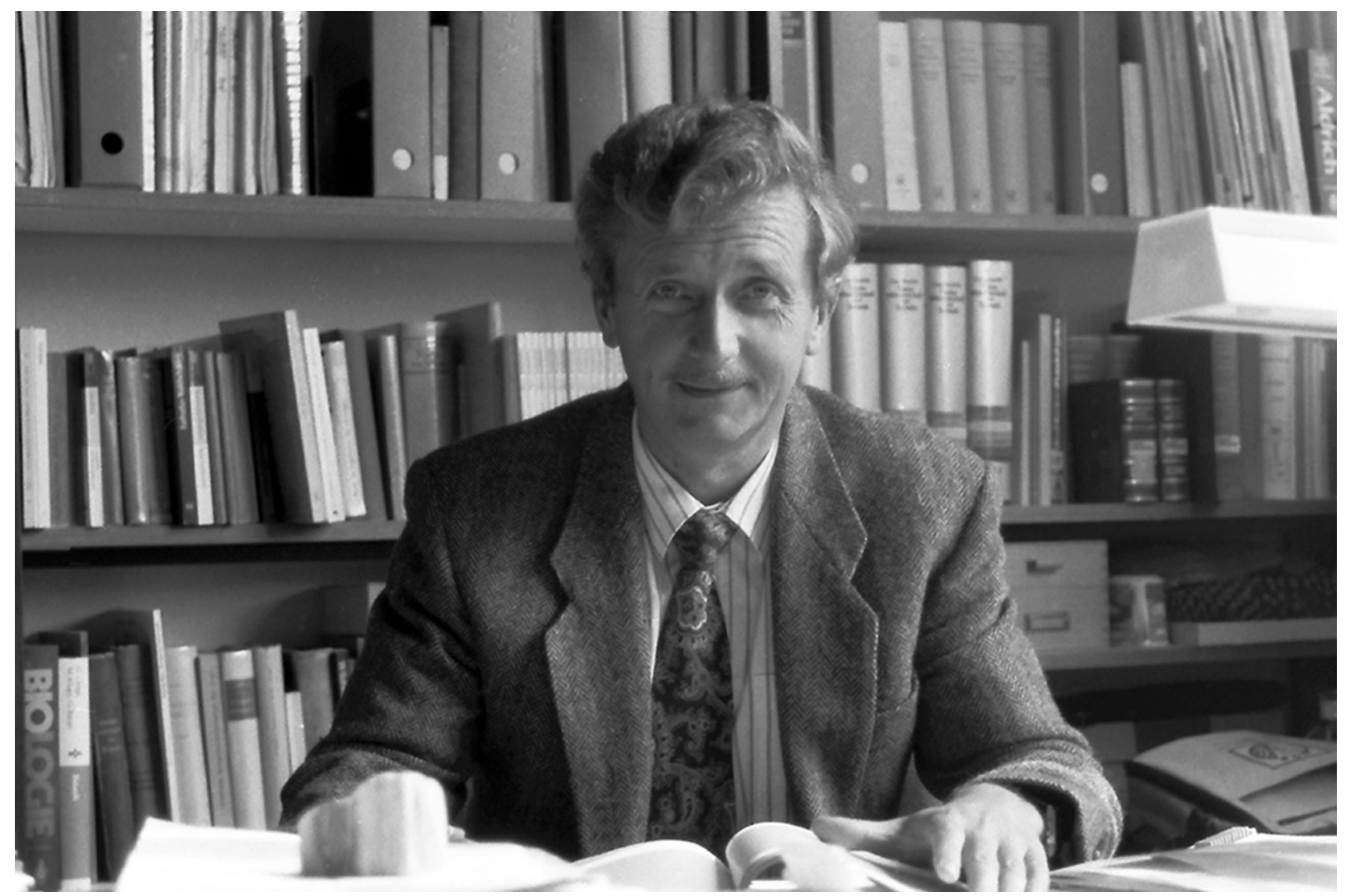

Fig. 1 Prof. Franz Oberwinkler at his office (in 1990s)

Takayuki Aoki

taoki@affrc.go.jp

1 Genetic Resources Center, National Agriculture and Food Research Organization (NARO), 2-1-2 Kannondai, Tsukuba, Ibaraki 305-8602, Japan
Dr. Franz Oberwinkler was an eminent mycologist, especially in taxonomy, systematics, evolution and ecology of basidiomycetes, with special reference to coevolution of fungi and plants. It is extremely difficult to list all of his outstanding, various and numerous achievements in mycology in a few pages. I would, however, like to provide 


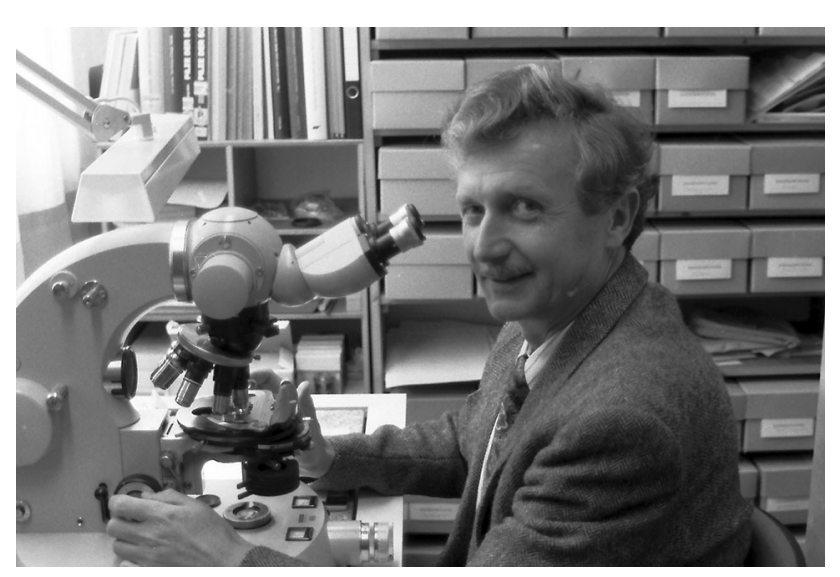

Fig. 2 Prof. Franz Oberwinkler at his personal working bench for microscopy (in 1990s)

a tiny window to introduce his so productive life history, also by the aid of Oberwinkler (2012).

Dr. Franz Oberwinkler was born in Bad Reichenhall, Oberbayern (Upper Bavaria) of Germany near the border to Austria. He studied biology, chemistry and geography at the Ludwig-Maximilians-University of Munich, and obtained his Ph.D. (Dr. rer. nat) in 1965 with a dissertation on "lower basidiomycetes" under the guidance of Prof. Dr. Josef Poelt. After promotion, he became a scientific assistant at the Research Group for Special Botany and Pharmacognosy in the University of Tübingen until 1967. From 1967 to 1972 he was a research assistant and a lecturer at the Institute of Systematic Botany, University of Munich and habilitated in 1972 to teach students as a "Privatdozent". From 1968 to 1969, he conducted his research work in Venezuela, at the Instituto Forestal Latinoamericano at Mérida, as a scientific expert of the Food and Agriculture Organization (FAO) of the United Nations (Fig. 2).

He succeeded Prof. Dr. Karl Mägdefrau (as Alpinist and Botanist) on the chair of Special Botany and Mycology ("Lehrstuhl für Spezielle Botanik und Mykologie") at the Eberhard-Karls-University of Tübingen in 1974. From 1974 to 2008 he was also the director of the Botanical Garden of the University of Tübingen. Dr. Franz Oberwinkler became an Emeritus Professor of the University in 2008.

Dr. Franz Oberwinkler was eminent for his great monumental works in mycology, i.e., taxonomy, morphology and systematics of the Basidiomycota and fungal ecology, together with his well-designed and well-equipped Research Group for the school of Special Botany and Mycology. However, these achievements were not established in 1 day, but are based on continuous, uninterrupted accumulation of study results by the members of his research group. Research activities of the group always started in the field, considering fungi in their habitats.
Fieldwork is important for observation, recognition, collection, identification, and finally for culturing fungi. Based on the primary concept that the fungal habitat is the main ecological component, roles of plants and animals as the obligate interacting partners of fungi were considered and evaluated appropriately. At first, careful observation and analyses of cellular structures of saprobic and parasitic basidiomycetes were strongly recommended in the group. An illustration training 'course', offered to his school, is one of the expression of this study principle. To participate in the 'course', everybody including Prof. Oberwinkler himself contributed a hand-made illustration of a fungal species relevant for their own study and explained their microscopic structures observed in detail. In the research group, light microscopes were well equipped in every laboratory and there was a well-designed laboratory for electron microscopy. Results of light microscopy and electron microscopy were compared to one another and combined. The group also dealt with isolation of fungi and characterization of antibiotic substances produced by selected species of fungi. This working orientation also led the group to carry out extensive studies on soil and woodinhabiting fungi, including mycorrhizal fungi, of German native forest trees, in connection to the research framework against the forest damage, e.g., the famous tree declining by acid rain and other environmental pollutants in the Black Forest. After the introduction of DNA sequencebased molecular phylogeny in mycology, this group applied the techniques initiatively for the optimization of knowledge on biodiversity, ecology and phylogeny of fungi and led the world mycology by suggesting alternative systematic groups of fungi based on their results of evolutionary phylogeny, especially on the systematics of Basidiomycota.

Until very recently, taxa in the Basidiomycota have been classified at higher ranks based mainly on structures of fruitbodies or basidiomes, together with morphology of basidia/basidiospores as microscopic characters. Lower and higher basidiomycetes have also been long categorized and recognized based on the superficial morphological similarities of fruitbodies. Based on his accumulated results of detailed structural examination on fruitbodies of various basidiomycetous species, distributed in the whole range of the fungal group, Oberwinkler (1977) suggested that the known variable fruitbody structures, such as corticioid, merulioid, poroid, stereoid, hydnoid, clavarioid, cantharelloid, boletoid, agaricoid or gasteroid, were considered as multiple events that happened independently from the overall evolution of basidiomycetous fungi. In other words, fruitbody structures are taxonomically important as secondary characters within a group, but do not reflect the overall evolutional history of the basidiomycetes. This suggestion was made much earlier than the introduction of 
DNA sequencing techniques to mycology that are now commonly used for fungal phylogenetic studies. He proposed two functional hypotheses, i.e., (1) Widening of the hymenium or hymenophore may lead to multiplication of numbers of spore production; (2) Raising-up and separation of the hymenium or hymenophore from the substrate surface (from a console-formed fruitbody to a stalked one) may facilitate spore release. This consideration may come from the working principle of Dr. Franz Oberwinkler considering fungi from its habitat.

Based on recent progress of molecular phylogenetic analyses of fungi, his consideration and suggestion for this alternative orientation of basidiomycete taxonomy, e.g., on Polyporales, Russulales, Thelephorales, Hymenochaetales and Boletales is becoming realized. Such a taxonomic rearrangement, irrespective of their fruitbody structures, is also proceeding in the former "Gasteromycetes" (currently called gasteroid fungi) as it was found to be an artificial class. This was also progressed in the former Heterobasidiomycetes, among which the Auriculariales, Sebacinales, and Dacrymycetales are currently considered as a part of Agaricomycotina, since phylogenetic studies confirmed that they are more distantly related to the Pucciniomycotina and Ustilaginomycotina.

There are many students, who grew up from his research group, working on various groups of basidiomycetes, e.g., the rust fungi (Pucciniomycotina) and smut fungi (Ustilaginomycotina), Exobasidiales (currently in Ustilaginomycotina), Tremellales, Dacrymycetales, Sebacinales, Auriculariales, Cantharellales, Hymenochaetales, Agaricales (Agaricomycotina), and more. Students of the school also conducted research on microscopic ascomycetous fungi, as saprobes (including soil-inhabitants), mycoparasites, plant parasites, bark-beetle symbiotic fungi, and yeast species from rhizospheres of plants and from galleries of bark beetles. Many of his students became leading mycologists in the various fields of mycology, as university professors and institute researchers.

His research group accepted many foreign guest scientists staying for longer periods, including Ph.D. students and post-doctoral researchers, as well as numerous short visitors. Collaboration with foreign mycologists also formed the basis of numerous outcomes. Especially joint studies with the late Dr. Robert Bandoni, University of British Columbia, Canada, concerning systematics of the heterobasidiomycetes which led to establishment of many unique new taxa, such as Atractogloea, Carcinomyces, Colacogloea, Cystofilobasidium, Entomocorticium, Stilbotulasnella, Tetragoniomyces and Trimorphomyces as new genera, Carcinomycetaceae, Chionosphaeraceae, Cystofilobasidiaceae, Pachnocybaceae and Tetragoniomycetaceae as new families, and Atractiellales and Graphiolales as new orders.

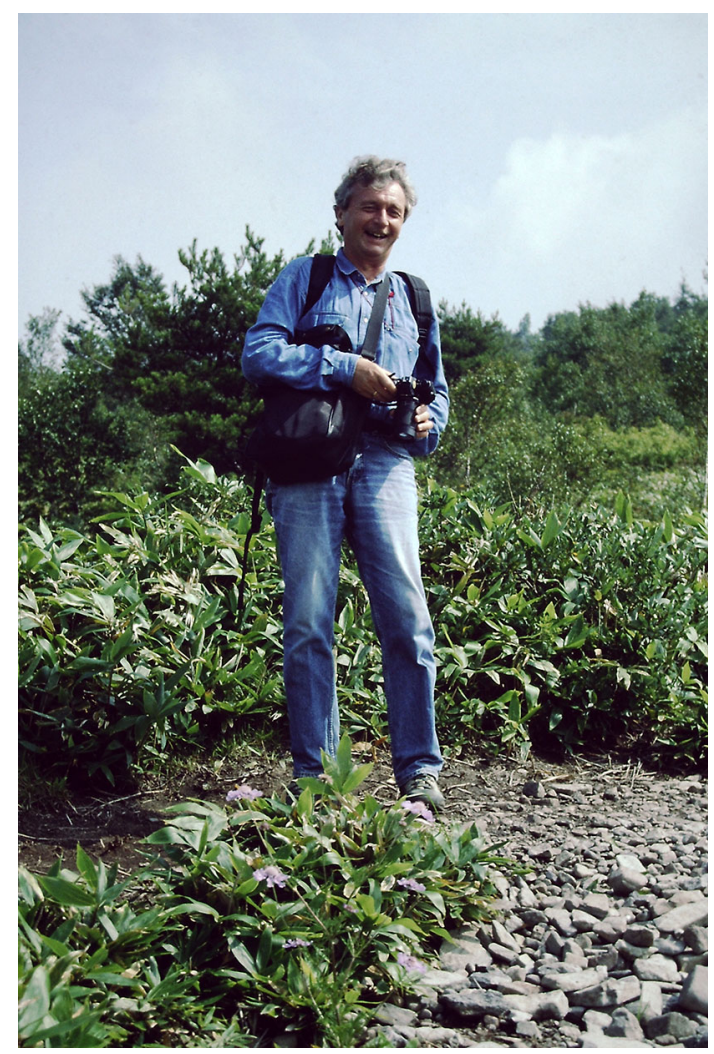

Fig. 3 Prof. Franz Oberwinkler enjoying comparison of highland vegetation at Mt. Neko, Nagano, Japan (in 1990s)

He was the first Editor-in-Chief of the English language journal, Mycological Progress, published by the German Mycological Society (DGfM) and spent his efforts for its development as the Editor-in-Chief during more than 14 years (from 2002 to 2016, vols. 1-15).

He personally enjoyed atmospheres and cultures of East Asian areas very much and often visited Japan, and Mainland and Taiwan of China, together with his family and students to contact his close friends there, as well as receiving young students from these countries (Fig. 3).

Finally, he was active as the President of the International Mycological Association (IMA) from 1994 to 1998 and held memberships of many mycological societies worldwide. He was awarded for the De Bary Medal of the International Mycological Association in 2010.

The sudden death of Dr. Franz Oberwinkler is for us very regretful, not only as we miss our great mycological teacher, but it is also like losing a monumental tower of mycology. However, I believe that his outstanding achievements in mycology will surely become succeeded and expanded by the very active and enthusiastic students who learned from him in his school, by considering it as a new starting point. 


\section{References}

Oberwinkler F (1977) Das neue System der Basidiomyceten. In: Frey W, Hurka H, Oberwinkler F (eds) Beiträge zur Biologie der niederen Pflanzen. G. Fischer Verlag, Stuttgart, pp 59-105
Oberwinkler F (2012) Mykologie am Lehrstuhl Spezielle Botanik und Mykologie der Universität Tübingen, 1974-2011. Andrias 19:23-110 